\title{
WORKING IN THE DIGITAL AGE: MERGING A STATUS QUO BIAS PERSPECTIVE AND REFLECTIVE PRATICE
}

\author{
Frederike Marie Oschinsky ${ }^{1}$, Hans Christian Klein ${ }^{2}$ and Bjoern Niehaves ${ }^{3}$ \\ University of Siegen, Germany
}

\begin{abstract}
The pillars of digital change (new role models, new competences, changed attitudes) are most visible in the everyday practice of staff. In the digital age of continuous transformations, we need a theoretical basis that is capable of describing an individual's behavior in situations of uncertainty, instability, uniqueness and value conflicts. We approach this theoretical gap by joining the vision of "Reflective Practice" (Schön, 1983) and the status quo bias perspective (Kim and Kankanhalli, 2009; Lee and Joshi, 2017). By proposing a three-step mixed-method study, we try to answer the question of how work can be actually designed in the digital age. Based on our insight, we seek to develop a guideline to help organizations frame the working conditions in a future-oriented and comprehensible way.
\end{abstract}

\section{KEYWORDS}

Digitalization, Digital Work, Rational Choice, Reflective Practitioner, Cognitive Bias, Status Quo Bias Perspective

\section{INTRODUCTION}

Digitization is changing the way we work and organize. The use of information technologies (IT) makes it possible to fulfil tasks more effectively and to maintain or even increase the quality of service and data security. At the same time, IT use can save time, reduce errors and streamline internal processes. Nevertheless, digital change is accompanied by new roles and modified needs for (IT) competence (e.g., Hill, 2014; Malsbender et al., 2014; Ogonek et al., 2018, 2016), as well as a changing attitude towards digital solutions (e.g., Ogonek et al., 2018). This triad has been intensively studied and provides the basis for our investigation.

In order to explain decision-making of employees in the digital age, we consider the fundamental work in decision research. Nobel prize winner Herbert A. Simon (e.g., Simon, 1944, 1946, 1997; see also Sherwood, 1990) has stated that employees do not have access to all the necessary information and cannot process all facts correctly. Rationality is 'bounded'. His work is more prominent than ever in the digital age. Despite the high value of using technologies, many benefit from them only to a limited extent and encounter IT with skepticism or even fear. They insist on learned procedures and known solutions, although this perseverance objectively entails disadvantages (e.g., temporal, financial and emotional costs). This behavior is known as 'status quo bias' (Kim and Kankanhalli, 2009; Polites and Karahanna, 2012; Lee and Joshi, 2017; Li et al., 2016).

Current acceptance models and their underlying theories (e.g., Davis, 1989) often neglect the explanatory power of the status quo bias. We rely on the work of "Reflective Practice" (Bousbaci, 2008; Habib, 2017; Schön, 1983) as it pioneered to include cognitive biases and heuristics to explain how people interpret their working life and shape their behaviour accordingly. For this reason, we propose to expand research on competence building in the digital age and to include the aspect of this cognitive bias in order to shape the education and training of staff. Our research question is: How can work in the digital age be actually designed? Based on our insight, we seek to develop a guideline to help organizations frame the working conditions in a future-oriented and comprehensible way. For addressing our objective, we briefly present the theoretical background and research framework and then discuss the structure of our three-step methodological approach. Finally, we give an outlook.

\footnotetext{
frederike.oschinsky@uni-siegen.de

2 christian.klein@uni-siegen.de

${ }^{3}$ bjoern.niehaves@uni-siegen.de
} 


\section{RELATED WORK}

In his seminal work "Reflective Practitioner - How Professionals Think in Action", Donald Schön (1983) develops the concept of practitioners, which goes far beyond experts using standard solutions (p.21). This concept is the basis for our further investigation. The concept consists of three parts (A) Knowing-in-Action (KiA), (B) Reflection-in-Action (RiA), and (C) Reflection-on-Action (RoA). The core of the concept is the phenomenon of $\mathrm{RiA}$, which therefore builds the focal point of our framework.

KiA. Knowledge often is an unconscious and partly subconscious process. It forms the basis for action. Knowledge can be achieved through repetitions in a repertoire of expectations, representations and techniques in the practice of the expert (ibid., p.60). The repetitions make knowledge more and more specialized.

RiA. In everyday life, practitioners apply knowledge tacitly and implicitly (e.g., implicit perceptions, judgements, and skills). Schön describes the phenomena with the phrases "thinking on your feet", "keeping your wits about you" or "learning by doing" (ibid., p.49-50; p.54). RiA is not a matter of conscious thinking, but of feeling and intuition. The practitioner acts and works on a task and - sometimes ad hoc - situations arise in which he automatically calls up his existing knowledge (ibid, p.50). One can understand this as 'rules of thumb', illustrating the proximity to heuristics and cognitive distortions (ibid, p.63). The knowledge of the practitioner (KiA) in a rationally bounded manner. RiA can be divided in three subcategories:

(1) Framing - F: First, the problem framework is defined. When a satisfying solution is found, the process stops. Every practitioner understands the task of finding a satisfactory solution as unique and has to define and frame the problem in the first step (ibid., p.129).

(2) Reframing - RF: Second, the problem frame might need to be reset and reframed due to the complexity of a problem. The focus of the practitioner will be shifted away from the problem at hand to a different perspective of the situation. This can open up new design possibilities. A practitioner needs to solve the new problem with a kind of craftsmanship (ibid, p.130).

(3) Experiment - X: Third, the practitioner has to try whether the new solution is satisfactory. It is a kind of experiment. The new solutions will be examined with a new problem framework. The practitioner succeeds in spontaneously comparing, evaluation and finally favoring solutions (ibid., p.130).

RoA. The practitioner thoroughly thinks about the result of the situation or task. This reflection improves the practitioner's way of approaching the next task. This helps to improve the 'processing economics' (ibid., p.60) and possibly leads to 'overlearning' (ibid. p.60-61). Thus, it automatically influences KiA.

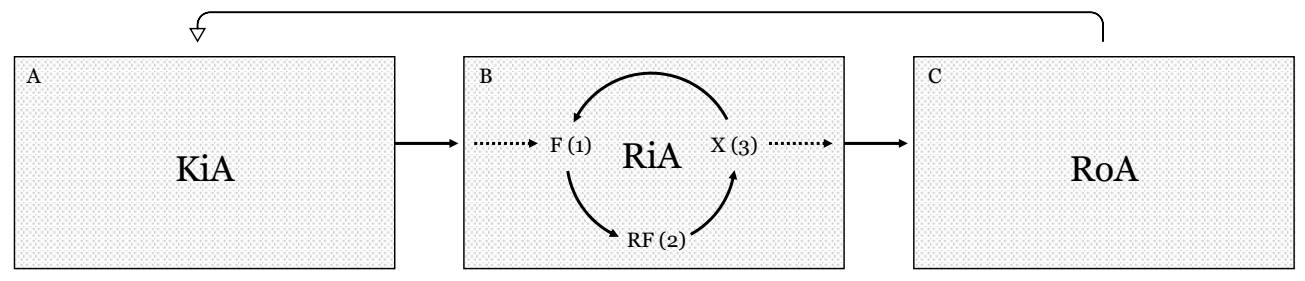

Figure 1. Reflection in Practice

Bounded rationality has its origins in the field of psychology (Tversky and Kahneman, 1974). Due to the explanatory power of the approach, it has been adopted in many other disciplines and serves to understand many previously puzzling phenomena. The approach follows the assumption that decisions are not always based on the weighing of costs and benefits. Instead, human judgment is influenced by heuristics and cognitive biases. Heuristics, or 'rules of thumb', help decision making in complex situations under uncertainty, and in situations that do not allow for long and reasoned reflection (Schön, 1983). However, cognitive biases, as systematic deviations from rationality, can lead to suboptimal and undesirable outcomes, for instance, because not all alternatives were considered or the effort of action wrongly estimated (Kahneman, 2003).

Undesirable outcomes are what we often observe when someone sticks only to a habitual decision making and behavior, even when better alternatives exist (e.g., the department head does not consider IT solutions, although digital workspaces require digital components (Fleischmann et al., 2014)). Samuelson \& Zeckhauser (1988) were at the forefront to distinguish between three main constructs that influence the so called 'status quo bias': rational decision-making, cognitive misperception, and psychological commitment. 
In IS research, Lee \& Joshi (2017) supplement the perspective and offer the constructs. In particular, the authors adopted the categories and subdivided them even further. The dimensions are briefly summarized in the following.

Rational decision-making is not always possible under uncertainty. Uncertainty is the individuals' lack of information and/or expertise about the alternatives, which may impose search and analysis costs, and lead to decision paralysis (Samuelson and Zeckhauser, 1988). The concept was later on divided into anxiety costs as well as search and analysis costs (Lee and Joshi, 2017).

Cognitive misperception consists of loss aversion and anchoring effects addressing the perceived value. Loss aversion illustrates that individuals weigh losses heavier than gains in making decisions (e.g., Kahneman and Tversky, 1979; Kahneman, 2011). Anchoring effects refer to the individuals' propensity of setting a starting value and then assessing changes with reference to the initial state (Tversky \& Kahneman, 1974).

Psychological commitment has three parts: sunk costs, regret avoidance and the effort to feel in control. Sunk costs in sequential decisions describe the continual selection of the same choice, where individuals' desire to justify previous commitments to a course of action by making subsequent commitments (Samuelson and Zeckhauser, 1988). Regret avoidance, which was later on divided into the categories regret avoidance and social norms (Lee and Joshi, 2017) shows that individuals are likely to avoid consequences in which they could make the wrong choice, even if in advance the decision appeared correct given the information available at the time (Samuelson and Zeckhauser, 1988). Finally, the effort to feel in control, which was later on added by the term 'self-efficacy' (Lee and Joshi, 2017), refers contexts where people have the freedom to make choices and thus perceive that they control the situation' (Samuelson and Zeckhauser, 1988).

\section{FRAMEWORK}

In merging the status quo bias perspective and reflection in action, we focus on two important points:

"Problem-ignoring". Type I-III occur when the application of existing knowledge (e.g., executing a standard solution) happens without reflection, and is thus based on a bias. A suboptimal solution thus appears to be the 'best' answer to a task.

"Not getting out of the wheel". Type IV-VI occur when the evaluation of the variants is not done rationally, but based on biases. Therefore, a rationally better solution is discarded.

After highlighting these two points, we identify two prominent cases where it is absolutely necessary to think rationally. Thus, the status quo bias has to be comprehensibly reduced. First, thorough RiA must be made possible. The practitioner has to recognize a situation as unique and new and thus frame a new problem in it, which involves reasoning and weighing of alternatives. Second, if the practitioner in the iterative process of RiA has to somehow recognize an outcome of his experiments as a satisfying solution. He has to formulate: "We stop experimenting. This is the solution and we start with the implementation!" The two cases where it is absolutely necessary to think rationally, will be acknowledged in our future studies.

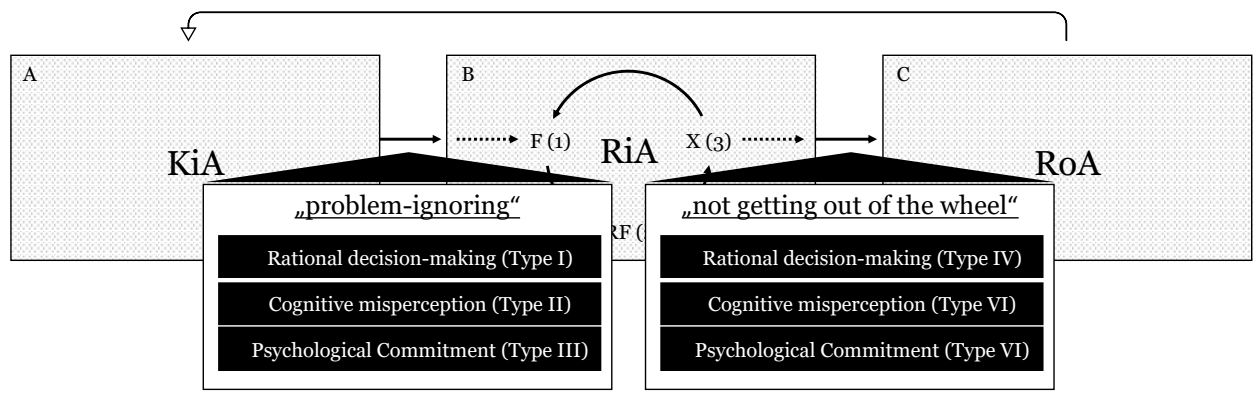

Figure 2. "Bounded" Reflection in Practice 


\section{RESEARCH AGENDA AND CONCLUDING REMARKS}

Our aim is to develop an integrated model based on the status quo bias perspective and reflection in action. In order to obtain a holistic view of technology acceptance and the intended use of staff in the digital age among different organizations, we will conduct a preliminary mixed-method study in a municipality. The study will also be carried out in one small-sized and one medium-sized enterprise and a university of applied sciences. The three-stage mixed-methods study consists of a qualitative preliminary study, a pilot test and a quantitative survey. A subsequent workshop, which can be attended analogously and digitally, aims to mirror the results in practice, draw conclusions about new job profiles and shape and strengthen leadership. The findings of the study will be summarized and made available to the public free of charge. The study is structured as follows:

Qualitative preliminary study. Focus group with public administration managers to develop an activity scenario that includes innovative technologies (e.g., artificial intelligence). Moreover, we present the status quo bias perspective and the reflection in action approach. Thereupon, we identify missing variables.

Pilot test. The newly developed scenario is used as a priming tool for our questionnaire. The pilot test itself contains this scenario and the extended list of variables. In order to test the comprehensibility of our questions and the meaningfulness of the formulations, we perform a test with a small sample of employees $(\mathrm{N}=5)$.

Survey. After revising the questionnaire, we carry out a large-scale online survey $(\mathrm{N}=300)$. The aim is to develop our model in an explorative manner and to search for significant correlation and cause-effect relationships. After conscientious data cleansing and analysis, the results will be summarized. To present and discuss the project results, a workshop will be held, which can be attended in analogue and digital form. The aim is a future-oriented discourse on competence development and digital work.

To conclude, we seek to develop a guideline to help organizations frame the working conditions in a future-oriented and comprehensible way. By proposing a three-step mixed-method study, we try to answer the question of how work can be actually designed in the digital age. Because the pillars of digital change (new role models, new competences, changed attitudes) are most visible in the everyday practice of staff, we seek to test the newly developed theoretical basis (joining the status quo bias perspective and reflection in action). The findings of our study can be applied and refined in various settings of digital work.

\section{REFERENCES}

Bousbaci, R., 2008. "Models of Man" in Design Thinking: The "Bounded Rationality" Episode. Design Issues 24, 38-52.

Davis, F.D., 1989. Perceived Usefulness, Perceived Ease of Use, and User Acceptance of Information Technology. MIS Quarterly 13, 319-340.

Fleischmann, M., Amirpur, M., Benlian, A., Hess, T., 2014. Cognitive Biases in Information Systems Research: A Scientometric Analysis. ECIS 2014 Proceedings.

Habib, H., 2017. A Study of Reflective Practice and its Role For Teachers 5, 4.

Hill, H., 2014. Wandel von Verwaltungskultur und Kompetenzen im digitalen Zeitalter, in: Transparenz, Partizipation, Kollaboration. Nomos Verlagsgesellschaft mbH \& Co. KG, pp. 123-148.

Kahneman, D., 2011. Thinking, Fast and Slow. Penguin, London.

Kahneman, D., 2003. Maps of Bounded Rationality: Psychology for Behavioral Economics. American Economic Review 93, 1449-1475.

Kahneman, D., Tversky, A., 1979. Prospect Theory: An Analysis of Decision under Risk. Econometrica 47, 263.

Kim, H.-W., Kankanhalli, A., 2009. Investigating User Resistance to Information Systems Implementation: A Status Quo Bias Perspective. MIS Quarterly 33, 567-582.

Lee, K., Joshi, K., 2017. Examining the use of status quo bias perspective in IS research: need for re-conceptualizing and incorporating biases. Inf. Syst. J. 27, 733-752.

Li, J., Liu, M., Liu, X., 2016. Why do employees resist knowledge management systems? An empirical study from the status quo bias and inertia perspectives. Computers in Human Behavior 65, 189-200.

Malsbender, A., Hoffmann, S., Becker, J., 2014. Aligning Capabilities and Social Media Affordances for Open Innovation in Governments. Australasian Journal of Information Systems 18, 317-330. 
Ogonek, N., Distel, B., Rehouma, M.B., Hofmann, S., Räckers, M., 2018. Digitalisierungsverständnis von Führungskräften. Berichte des NEGZ, Nationalen E-Government Kompetenzzentrum e.V., Berlin, Münster 2.

Ogonek, N., Räckers, M., Becker, J., 2016. Rollen und Kompetenzen für eine erfolgreiche öffentliche Verwaltung im digitalen Zeitalter. Studie im Auftrag des IT-Planungsrats, Nationalen E-Government Kompetenzzentrum e.V., Berlin, Münster.

Polites, G.L., Karahanna, E., 2012. Shackled to the Status Quo: The Inhibiting Effects of Incumbent System Habit, Switching Costs, and Inertia on New System Acceptance. MIS Quarterly 36, $21-42$.

Samuelson, W., Zeckhauser, R., 1988. Status quo bias in decision making. Journal of Risk and Uncertainty 1, 7-59.

Schön, D.A., 1983. The reflective practitioner: How professionals think in action. Routledge.

Sherwood, F.P., 1990. The Half-Century's "Great Books" in Public Administration. Public Administration Review 50.

Simon, H.A., 1997. Administrative Behavior, 4th ed. Free Press, New York.

Simon, H.A., 1946. The Proverbs of Administration. Public Administration Review 6, 53-67.

Simon, H.A., 1944. Decision-Making and Administrative Organization. Public Administration Review 4, 16.

Tversky, A., Kahneman, D., 1974. Judgment under uncertainty: Heuristics and biases. science 185, 1124-1131. 